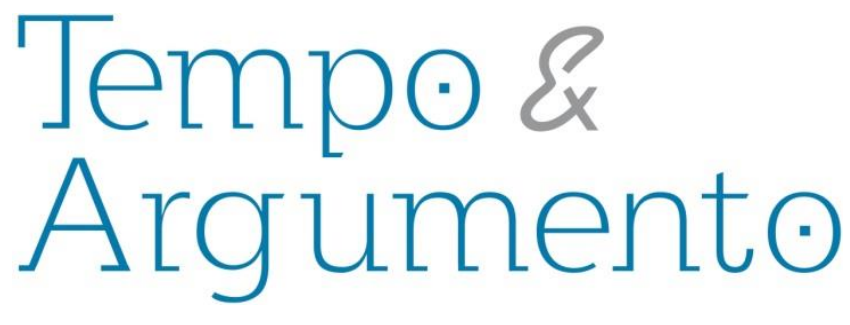

\title{
Atuação militante de Lélia Gonzalez na discussão da Constituição Federal de $1988^{1}$
}

\begin{abstract}
Resumo
Nos aproximamos da comemoração dos trinta anos de promulgação da famosa "constituição cidadã". O fato motiva uma reflexão sobre a atuação das entidades civis e de ativistas no processo de discussão do documento e de suas conquistas. O objetivo do presente artigo é compreender a participação da militante Lélia Gonzalez na subcomissão que discutiu questões relacionadas aos negros, bem como, as demandas apresentadas e os embates gerados. As fontes exploradas são a biografia da ativista, escrita por Ratts e Rios, e a Ata da sétima reunião da Subcomissão de Assembleia Nacional Constituinte, intitulada "Subcomissão dos Negros, Populações Indígenas, Pessoas Deficientes e Minorias", na qual Lélia palestrou. De maneira geral, a participação da militante indica os elementos básicos das demandas do movimento negro contemporâneo e a apreensão da validade de seus discursos não parece ter sido unânime entre os constituintes. Contudo, a participação de ativistas na elaboração da Constituição cria a oportunidade de contato dos parlamentares com argumentos legitimadores da causa negra e de visibilidade para demandas sociais.
\end{abstract}

\author{
Mírian Cristina de Moura Garrido \\ Doutora em História e Sociedade pela \\ Universidade Estadual Paulista "Júlio de \\ Mesquita Filho", Campus de Assis (UNESP). \\ Realiza atualmente Estágio Pós-Doutoral em \\ História na Universidade Federal de São Paulo \\ (UNIFESP). \\ Guarulhos - SP - Brasil \\ miriangarrido@hotmail.com
}

Palavras-chave: Lélia Gonzalez. Movimento Negro

Contemporâneo. Constituinte.

\section{Para citar este artigo:}

GARRIDO, Mírian Cristina de Moura. Atuação militante de Lélia Gonzalez na discussão da Constituição Federal de 1988. Tempo e Argumento, Florianópolis, v. 10, n. 25, p. 435 - 463, jul./set. 2018.

\section{DOI: $10.5965 / 2175180310252018435$}

http://dx.doi.org/10.5965/2175180310252018435

\footnotetext{
${ }^{1}$ As discussões deste artigo fazem parte de pesquisa fomentada pela Fundação de Amparo à Pesquisa do Estado de São Paulo (FAPESP), processo nº 2013/14210-7
} 


\title{
Militant action of Lélia Gonzalez in the discussion of the Federal Constitution of 1988
}

\begin{abstract}
We are approaching the commemoration of the thirty years of the promulgation of the famous "citizen constitution", which motivates a reflection of the actions of civil entities and activists in the process of discussing the document and its achievements. The objective of this article is to understand the participation of the militant Lélia Gonzalez in the subcommittee that discussed issues related to african-brazilian, as well as, presented demands and conflicts generated. The sources explored are the biography of the activist, written by Ratts and Rios, and the minutes of the seventh meeting of the Subcommittee of the National Constituent Assembly entitled "Subcommittee on African-brazilians, Indigenous Populations, Persons with Disabilities and Minorities", in which Lélia spoke. In general, the participation of the militant indicates the basic elements of the demands of the contemporary african-brazilian movement, and its apprehension between the constituents does not seem to be unanimous. However, the participation of activists in the discussion of Constituition Assembly creates the opportunity of the contact of congressmen with arguments legitimating the black cause and visibility for social demands.
\end{abstract}

Keywords: Lélia Gonzalez. Contemporary African-Brazilian movement. Constitutional.

\section{Introdução}

A mobilização das entidades civis para se fazerem presentes nas discussões da Constituição Federal de 1988 foi intensa e justificada pela necessidade de legislação que reconhecesse suas demandas. Esse foi o caso do movimento negro contemporâneo. Nos aproximamos da comemoração dos trinta anos de promulgação da famosa "constituição cidadã", o que motiva uma reflexão da atuação de militantes no processo de discussão do documento e de suas conquistas. O presente artigo se apresenta com o objetivo de compreender a participação da militante Lélia Gonzalez na subcomissão que discutiu questões relacionadas aos negros, bem como, quais eram as demandas apresentadas e os embates gerados. 
O artigo utiliza como fonte a biografia de Gonzalez, escrita por Flavia Rios e Alex Ratts (2010), e a Ata da Subcomissão de Assembleia Nacional Constituinte, intitulada "Subcomissão dos Negros, Populações Indígenas, Pessoas Deficientes e Minorias", documento composto pela transcrição dos debates ocorridos na reunião do dia 28 de abril de 1987, que contou com a participação de Lélia Gonzalez.

A abordagem historiográfica apresentada está amparada na concepção que toma sujeitos como atores políticos, cujo próprio sentido de político está ampliado (RÉMOND, 1999). Diz-se que o sentido foi ampliado, pois não se trata mais de um esforço historiográfico que celebra nomes de sujeitos hegemônicos, das estruturas políticas e que silencia sujeitos marginalizados.

\section{Lélia Gonzalez, entender a trajetória para compreender os discursos}

É fundamental compreender a trajetória de Lélia Gonzalez, apreendendo, concomitantemente, possíveis motivos que levaram as entidades negras a escolherem Lélia como uma das palestrantes da Subcomissão. A história de vida da militante é, também, um indicativo das demandas que apresentou na reunião em que palestrou. Para tanto, faço uso da biografia escritapor Alex Ratts e Flavia Rios (2010) sobre a militante.

Biografar indivíduos não pertencentes aos círculos hegemônicos (econômico, político ou cultural) é sempre um desafio. Peleja que o Selo Negro Edições parece ter tomado para si com a Coleção Retratos do Brasil Negro². Como alertam Alex Ratts e Flavia Rios,

Há dificuldades específicas de levantar a trajetória de pessoas públicas que não pertencem a circuitos hegemônicos de poder. Em geral, seu espólio se perde ou fica disperso com amigos e/ou parentes, sendo de difícil acesso para pesquisadores. É o que costuma acontecer com intelectuais negros brasileiros. E foi o que aconteceu com Lélia Gonzalez no que diz respeito a documentos pessoais, originais de suas publicações, fotografias etc. (2010, p. 16)

\footnotetext{
${ }^{2} \mathrm{O}$ esforço remonta à publicação de biografias sobre: Sueli Carneiro, Abdias do Nascimento, Nei Lopes, Centro de Cultura e Arte Negra, Cruz e Souza, João Cândido, Lima Barreto, Luiz Gama, além do já mencionado livro sobre Lélia Gonzalez. Grupo Summus. Disponível em: <http://www.gruposummus.com.br/selonegro/ colecao/Retratos\%20do\%20Brasil\%20Negro $\geq$. Acesso em: 12 jul. 2017.
} 
Ainda assim, a coleta de informações em acervos (8) ou entre indivíduos (23) que tiveram alguma relação com a biografada, permitiu acesso a fontes variadas sobre a militante ou produzidas por ela.

É importante destacar que apesar das dificuldades de biografar sujeitos não hegemônicos, a trajetória de Lélia Gonzalez tem sido alvo de reflexões por parte de pesquisas científicas, graças a importância da atuação militante e acadêmica (indissociáveis para a ativista). É o caso das dissertações de mestrado de Raquel Barreto (2005) e Elizabeth Viana (2006) e também de reflexões (derivadas de pesquisas acadêmicas) de Luiza Bairros (2006) e Cláudia Cardoso (2014). Autoras cuja atuação militante dentro do movimento negro é também conhecida.

Nascida em fevereiro de 1935, décima sétima filha de um total de dezoito, com mãe indígena, doméstica, e pai negro, ferroviário, Lélia Gonzalez narra uma vida de muito trabalho entre seus irmãos, tendo sido beneficiada com um estudo longevo e de qualidade por excepcionalidades. Benefícios esses advindos de ser a mais nova dentre os irmãos, da compaixão de uma família italiana para a qual a mãe prestou serviços de ama de leite, e de ter o irmão logrado êxito no futebol carioca (RIOS; RATTS, 2010, p. 24-31). A formação privilegiada - se comparada à realidade da maioria dos negros brasileiros -, que Ihe possibilitou formação universitária e domínio de línguas estrangeiras, legou a Lélia não apenas conhecimento formal, mas uma rejeição do pertencimento racial:

Fiz escola primária e passei por aquele processo que eu chamo de lavagem cerebral dado o discurso pedagógico brasileiro, porque, na medida em que eu aprofundava meus conhecimentos, eu rejeitava cada vez mais minha condição de negra. $\mathrm{E}$, claro, passei pelo ginásio, científico, esses baratos todos. (GONZALEZ, 1979 Apud RIOS; RATTS, 2010, p. 31)

Graduada em História, Geografia e Filosofia pela Universidade Estadual do Rio de Janeiro (1958 e 1962, na época, Universidade Estadual da Guanabara), Lélia Gonzalez desempenhou profissionalmente a função de professora, inicialmente em colégios de nível médio e, posteriormente, em universidades. Fotos do acervo pessoal de Ana Felippe (disponibilizados aos biógrafos) mostram uma Lélia Gonzalez professora, posando na formatura com um vestido recatado e tradicional de época, peruca lisa e penteada. A 
adoção de padrões de beleza e comportamento são narrados pela militante como forma de se fazer pertencer aos espaços notadamente não negros, tal como a universidade. Nesse sentido, a textura do cabelo ganha uma dimensão especial, pois é uma questão central nas discussões raciais, nas quais a recusa de pertencimento racial é evidente no distanciamento da herança genética do cabelo crespo³.

Outro elemento de rejeição étnico-racial, segundo a própria Lélia, teria sido a escolha do marido, um homem branco espanhol, colega de faculdade. Ironicamente, é o matrimônio que redefine o pertencimento da futura militante. Recusada como esposa legítima pela família do marido e questionada por ele sobre sua falta de pertencimento, a trajetória de Lélia Gonzalez toma novos rumos.

Mas quando chegou a hora de casar, eu fui me casar com um cara branco. Pronto, daí aquilo que estava reprimido, todo um processo de internalização de um discurso da "democracia racial" veio à tona, e foi contato direto com uma realidade muito dura. A família do meu marido achava que o nosso regime matrimonial era, como eu chamo, de "concubinagem", porque mulher negra não se casa legalmente com homem branco; é uma mistura de concubinato com sacanagem, em última instância. Quando eles descobriram que estávamos legalmente casados, aí veio o pau violento em cima de mim; claro que eu me transformei numa "prostituta", numa "negra suja" e coisas desse nível... (PEREIRA; HOLLANDA, 1979 Apud RIOS; RATTS, p. 52)

A relação conturbada com a família do marido (Luiz Carlos Gonzalez) e o falecimento trágico deste (não há referência de data do casamento ou falecimento) e de sua mãe (1967), parecem ter se tornado estopins para o envolvimento de Lélia em discussões políticas e uma (re)apreensão de sua trajetória. Surgiria dali a militante das causas negras e feministas. Para tal, Lélia ainda casaria com outro homem, "[Vicente Marota] um mulato que procurava fugir de si próprio" (p. 59), o que resultaria na busca de ajuda na psicanálise.

Tive que parar num analista, fazer análise etc. e tal, e a análise neste sentido me ajudou muito. A partir daí fui transar meu povo mesmo, ou seja, fui transar candomblé, macumba, essas coisas que eu chamava de primitivas. Manifestações culturais que eu, afinal de contas, com uma formação em filosofia, transando uma forma cultural ocidental tão

\footnotetext{
3 Conferir: XAVIER, Giovana. Brancos de Almas Negras? Beleza, racialização e cosmética na imprensa negra
} pós-emancipação (EUA, 1890-1930). Tese em História, Universidade Estadual de Campinas, 2012. 
sofisticada, claro que não podia olhar como coisas importantes. Mas enfim, voltei às origens, busquei minhas raízes. (PEREIRA; HOLLANDA, 1979 Apud RIOS; RATTS, p. 60-61)

A partir daí, Lélia passa a reinterpretar a experiência diaspórica africana na América. Dentre elas, a questão religiosa, aproximando-se do candomblé, que "se tornou uma referência poética e imagética para Lélia Gonzalez, presente aqui e acolá nos seus textos, inclusive nos ensaios de caráter mais político" (RIOS; RATTS, p. 64). Sua nova postura acompanhava uma mudança estética (cabelos black power e roupas de cores vivas, identificados com a cultura negra estadunidense e africana), como também uma ação de intervenção. Nesse sentido, articula cursos sobre cultura afro-brasileira, produz academicamente sobre os temas que agora lhe ocupavam a atenção, e participa de entidades negras de cunho político e cultural (tais como o Grêmio Recreativo de Arte Negra Escola de Samba Quilombo e o Movimento Unificado Contra a Discriminação Racial).

Característico desse movimento negro dos anos 1970 e 1980, Lélia, como liderança, torna-se, também, indivíduo de referência dentro e fora do movimento, tendo suas ideias expostas em jornais negros e em periódicos de grande circulação. Em consequência, suas ações passam a ser vigiadas pela polícia política atuante na Ditadura Civil-Militar brasileira, uma vez que discussões sobre raça eram ilegais no período (BARRETO, 2007).

A década de 1970 não representou o surgimento das discussões raciais somente para Lélia. Nesse período, uma série de mulheres e homens negros passam a se agrupar em prol das discussões raciais e atuar no território brasileiro. Abarcando expressões diversas, tais como o afro-axé baiano e cursos paulistanos sobre cultura afro-brasileira, entidades negras surgiram de Sul a Norte do país (ALBERTI; PEREIRA, 2007).

Mesmo que diversos em suas essências, esses grupos unem-se por alguns elementos centrais, sendo estes: denúncia do mito da democracia racial; busca por uma atuação política e apresentação de demandas aos poderes públicos; exortação de uma cultura afro-brasileira forjada na experiência escravista e pós-escravista; denúncia da discriminação racial, inclusive institucional; importância da educação e valorização de 
No campo da política partidária, ainda que receosa do comprometimento partidário com as causas negras, Lélia Gonzalez filia-se ao Partido dos Trabalhadores (PT), recém-criado e originário da classe trabalhadora de São Paulo que ganhou destaque nacional pelas greves realizadas no $A B C$ no final da década de 1978. Entrevistas dadas no período de sua filiação e na campanha para deputada federal, em 1982, indicam a crença da ativista no caráter diferenciado do PT - uma vez que o partido seria oriundo das classes mais baixas e trabalhadoras -, não havendo "no partido um senhor" (Apud RIOS; RATTS, p.116). Embora não obtenha sucesso no pleito, torna-se assessora de Benedita da Silva, que foi eleita vereadora em 1983 pelo PT-RJ. Em 1986, agora filiada ao PDT, cujas articulações de Leonel Brizola, Darcy Ribeiro e Abdias do Nascimento pesaram na escolha partidária, Lélia Gonzalez busca, mais uma vez, aprovação eleitoral para deputada estadual e, novamente, não é eleita, encerrando as tentativas de obter cargo político eletivo.

Na época de sua participação na Reunião da Subcomissão da Constituição, Lélia fazia parte do Conselho Nacional dos Direitos das Mulheres - gestão 1985 a 1989 -, submetido ao Ministério da Justiça e criado no governo José Sarney, mas originário das reivindicações junto a Tancredo Neves, ainda enquanto governador de Minas Gerais. $\mathrm{O}$ Conselho teria, originalmente, poder de promoção de políticas de eliminação da discriminação à mulher em todo âmbito nacional, mas também se articulou nas discussões da elaboração da constituinte (RIOS; RATTS, 2010, p. 105-107).

Atuante em diferentes entidades negras desde a década de 1970, acadêmica reconhecida nacional e internacionalmente (nas décadas de 1980 e 1990 palestrou em inúmeras instituições de ensino estadunidenses e africanas) por suas reflexões sobre a questão racial brasileira e inserida nos espaços da política partidária, Lélia Gonzalez representava um nome de extrema relevância para representar as demandas do segmento negro da população junto aos deputados e senadores constituintes. 
Isto posto, podemos afirmar que o campo político foi visualizado por Lélia Gonzalez como arena válida para legitimar demandas sociais. O fenômeno, não exclusivo do movimento negro, nem da realidade brasileira, modifica também as apreensões epistemológicas do Estado. Assim como prescrito por Réne Rémond (2003, p. 23), o Estado vivencia uma ampliação de seu sentido. Ele não só representa o grau máximo da organização política, como é, também, foco central das competições, instrumento das classes dominantes e expressão das relações de força; e viu grupos, até então secundários, aproximarem-se de si com o objetivo de reverter desequilíbrios de direitos e oportunidades históricos.

\section{Participação de Lélia Gonzalez nas discussões para elaboração da Constituição Federal de 1988}

Existe pouca literatura que se dedique a explicar o processo de formação da Constituinte. A pesquisa de Wilton Silva (1993), embora tenha por foco compreender a ação do movimento ecológico no processo de elaboração da Constituição, revela tramas do processo de elaboração da Carta Magna.

O primeiro movimento nesse sentido foi a formação da Comissão dos Notáveis, ou Afonso Arinos. Instituída por decreto ( $n^{\circ} .91 .450$, de 18 julho de 1985) do presidente José Sarney, a Comissão de Notáveis, como ficou conhecida, tinha por função construir um anteprojeto constitucional que auxiliaria no trabalho dos futuros constituintes. Para Wilton Silva, ainda que o texto possuísse um caráter progressista, foi rejeitado pela esquerda e pela direita. "Dos setores que se mostraram insatisfeitos com o Anteprojeto, as principais críticas diziam respeito à extensão do texto (minucioso e detalhista), ao forte conteúdo intervencionista e estatizante, e ao acentuado referencial ideológico (presente no capítulo sobre da ordem econômica e da ordem social) em detrimento de aspectos pragmáticos" (SILVA, 1993, p. 99).

Os favoráveis ao texto indicavam sua proximidade com os anseios da sociedade. Segundo Wilton Silva, pesou a crítica da falta de representatividade do texto, uma vez que os envolvidos na discussão e escrita não eram eleitos pelo voto. Esses aspectos, 

Assembleia Nacional Constituinte Exclusiva (SILVA, 1993, p. 59), coube aos eleitos do Senado e à Câmara, a elaboração da Carta Magna. Segundo o jornal Folha de S. Paulo, a situação foi agravada, pois $71 \%$ da população mostrava-se desinformada sobre a importância do momento constituinte, em grande parte, resultado do pouco amadurecimento do debate político, oriundo em especial dos próprios partidos (Apud SILVA, p. 62).

Para elaboração, discussão e aprovação da Constituição de 1988 (tendo os trabalhos iniciado em 1987), definiu-se a divisão dos constituintes (deputados e senadores) em oito comissões, subdivididas cada uma delas em três subcomissões, no total de 24. Cada uma das três subcomissões encarregou-se de elaborar um texto referente aos seus temas. Esses seriam apresentados ao Relator da Comissão de Sistematização, que criaria um texto integrando os anteriores. A Comissão de Sistematização, composta por noventa e três constituintes, apresentaria modificações ao texto resultando num Anteprojeto da Sistematização. Esse texto seria aberto em Plenário e alterado por emendas (inclusive as de iniciativa popular). Somente então seria votado, podendo sofrer emendas, o que nos levaria a $3^{\mathrm{a}}$ votação para gestar o texto final. No caso da Subcomissão dos Negros, Populações Indígenas, Pessoas Deficientes e Minorias, existiu ainda um quarto documento na segunda etapa. O documento em questão é o Substitutivo do Anteprojeto e que viria, no caso, na sequência das Emendas sugeridas ao Anteprojeto do Relator.

Segundo o pesquisador Wilton Silva, chama atenção o mecanismo das emendas populares:

Visando dar maior representatividade à futura carta, criou-se a possibilidade de intervenção popular no processo através de emendas, apresentadas sobre a forma de abaixo-assinados, subscritos por mais de 30.000 pessoas. Limitou-se, inexplicavelmente, a participação individual a no máximo três emendas, e onde cada emenda deve referir-se a um assunto. (SILVA, 1993, p. 94) 
O abaixo-assinado ainda deveria ser endossado por três entidades associativas para garantir autenticidade das assinaturas e dados do eleitor. Tais dificuldades impostas às participações populares levaram ao desenvolvimento de ações mais pontuais pelos setores envolvidos, embora tenham sido apresentadas 122 emendas populares.

Os militantes negros de diferentes entidades se fizeram presentes na Subcomissão de Assembleia Nacional Constituinte, intitulada "Subcomissão dos Negros, Populações Indígenas, Pessoas Deficientes e Minorias", integrante da VII Comissão da Ordem Social. O fato representava um ganho, na medida em que vislumbravam esses indivíduos a possibilidade de influir no texto da Constituição Federal. Por outro lado, havia uma limitação, uma vez que se tratava de uma subcomissão, dentro das outras vinte e três e cujas preocupações abrangiam uma série de grupos tidos como "minorias".

Essa articulação ganha conotação especial se for levada em conta a consideração da pesquisa de Wilton Silva:

Foi a movimentação dos setores organizados, como os movimentos sociais, a CNBB, a OAB, entre outros, que minimizaram o distanciamento entre a Assembleia Nacional Constituinte e as expectativas populares, onde essas expectativas foram divulgadas como pontos fundamentais a serem contemplados no processo constituinte. Esses setores se movimentaram, no sentido de criar respaldos constitucionais para suas reivindicações, buscando eleger candidatos comprometidos com suas lutas, e sensibilizar a sociedade para seus problemas e suas propostas. (SILVA, 1993, p. 64)

Na prática, apenas duas das 16 reuniões ( $7^{\mathrm{a}}$ e $10^{\mathrm{a}}$ reunião, dias 28 de abril e 04 de maio de 1987, respectivamente) foram destinadas às discussões sobre a questão do negro e, ainda assim, não de forma exclusiva. No caso da $10^{\mathrm{a}}$ reunião, além da temática étnica, discutiram-se os problemas e possíveis soluções para os deficientes visuais e a educação especial.

A Subcomissão teve por Presidente o deputado Ivo Lech (PMDB-RS); $1^{\circ}$ vicepresidente, Doreto Campanari (PMDB-SP); $2^{\circ}$ vice-presidente, Bosco França (PMDB-SE), e como relator, Alceni Guerra (PFL-PR). Sendo ainda titulares, os deputados constituintes: do PMDB, Ruy Nedel (RS), Hélio Costa (MG), José Carlos Sabóia (MA), Mattos Leão (PR), Mauro Sampaio (CE), Renan Calheiros ( $A L)$; do PFL, Jacy Scanagatta (PR), Salatiel 
Carvalho (PE); do PDT, Nelson Seixas (SP); do PT, Benedita da Silva (RJ) e o senador constituinte, Lourival Baptista (PDS-SE). A supremacia numérica de deputados do PMDB não está relacionada ao interesse desse partido pelo assunto das minorias; na verdade, reflete a vitória expressiva do partido na eleição que precedeu a constituinte.

\section{Sétima Reunião da Subcomissão dos Negros, Populações Indígenas, Pessoas Deficientes e Minorias}

Segundo Luciana Basílio (2004), estavam presentes na primeira reunião:

constituintes: Doreto Campanari (PMDB-SP), Alceni Guerra (PMDB-SE) [sic PFL-PR], Benedita da Silva (PT-RJ), Edivaldo Motta (PMDB-A), Salatiel Carvalho (PFL-PE), Almir Gabriel (PMDB-PA), Carlos Alberto Caó (PDT-RJ), Edmilson Valentim (PcdoB-RJ), Anna Maria Rattes (PMDB-RJ), Domingos Leonelli (PMDB-BA), Haroldo Sabóia (PMDB-MA), Osmir Lima (PMDB-AC), Ruy Nedel (PMDB-RS). (BASÍLIO, 2004, p. 70)

Segundo a Ata, também estavam presentes os Constituintes:

Bosco França (PMDB-SE) Hélio Costa (PMDB-MG) José Carlo Sabóia (PMDB-MA) Nelson Seixas (PDT-SP), Olívio Dutra (PT-RS). (DIÁRIO DA ASSEMBLÉIA NACIONAL CONSTITUINTE - SUPLEMENTO AO N. 62, 1987, p. 120)

Durante o andamento das discussões, é observada a chegada de outros integrantes: "gostaria de comunicar a presença na Mesa de S. Exº o Constituinte Almir Gabriel, Relator-Geral da Comissão Temática da Ordem Social, a qual está ligada à nossa Subcomissão" (Ivo Lech DIÁRIO DA ASSEMBLÉIA NACIONAL CONSTITUINTE SUPLEMENTO AO N. 62, 1987, p. 127); “[não mencionado até fazer uso da palavra estava também presente Carlos Alberto Caó] Sr. presidente, eu e o companheiro Olívio Dutra, que fazemos parte da Comissão de Ciência e Tecnologia e Comunicação, nos desdobramos para vir participar da reunião de hoje desta Subcomissão" (Carlos Alberto Caó, DIÁRIO DA ASSEMBLÉIA NACIONAL CONSTITUINTE - SUPLEMENTO AO N. 62, 1987, p. 133). 
Dos não ocupantes de cargos eletivos, mas presentes, a autora destacou a atuação de Lélia Gonzalez, caracterizada, por ela, como antropóloga da Pontifícia Universidade Católica do Rio de Janeiro e de Helena Teodoro, filósofa, na época professora da Universidade Gama Filho, e também coordenadora da Comissão Especial de Cultura Afro-Brasileira do município do Rio de Janeiro, e elencou a presença de outros na reunião

[e] outros representantes de organizações do movimento negro: Maria das Graças dos Santos - Movimento Negro Unificado (MNU); Murilo Ferreira - Fundação Afro-Brasileira do Recife; Lidia Garcia Mello - Centro de Estudos Afro-brasileiros de Brasília (CAEB); Orlando Costa - Instituto Nacional Afro-Brasileiro; Januário Garcia - Instituto de Pesquisa da Cultura Negra; Mauro Paré - Fundação Sango. (BASÍLIO, 2004, p. 70)

O destaque às presenças de Gonzalez e Teodoro, ratificado por Luciana Basílio, também consta na Ata da $7^{a}$. Reunião Ordinária da Subcomissão, pois ambas palestraram no dia para esclarecimento das questões que deveriam entrar no debate sobre o negro. É interessante que a pesquisadora e o redator da Ata não tenham caracterizado Lélia também como representante do Movimento Negro Unificado, o que de fato era na época. O fato é mencionado quando Benedita da Silva, compondo a mesa para auxiliar a presidência, apresentou a primeira expositora. Na apresentação, Benedita deixa claro que a importância de Gonzalez é tal que, para os envolvidos com o movimento negro, a expositora não necessitava de apresentações. Vale lembrar que Gonzalez foi assessora de Benedita da Silva na ocasião de seu primeiro mandato como vereadora do Rio de Janeiro e teria, segundo entrevistas dadas por ela, contribuído para a sua formação e conscientização a respeito das questões raciais. Para Helena Teodoro (ora grafado com H ora sem), os predicados acadêmicos foram descritos por Benedita, também acrescidos do envolvimento de Teodoro como militante do movimento negro.

Nas discussões transcorridas no período da tarde, integraram os debates parte das personalidades mencionadas no início do documento, acrescidas da participação do Professor Lauro Lima Santos Filho, psicólogo, professor da Associação do Ensino Unificado do Distrito Federal e Conselheiro do Memorial Zumbi; do Professor Paulo Roberto Moura; de Natalino Cavalcanti de Melo; de Raimundo Gonçalves dos Santos, 
Presidente do Núcleo Cultural de Girocan da Bahia; de Lino de Almeida, Coordenador do Conselho das Entidades Negras da Bahia; de Marcelino Campos Dominiques; e de Valdomiro de Souza. Alguns indivíduos não foram caracterizados em sua atuação na Ata; muito possivelmente, os que foram identificados de forma mais pormenorizada, o foram porque fizeram uso da palavra.

A primeira a fazer uso da fala foi Lélia Gonzalez ${ }^{4}$. Seu discurso enfatizou a negação da importância do negro na construção da sociedade; a prioridade histórica dada aos brancos na imigração como forma de embranquecimento da população brasileira; uma conduta política e cultural das instituições e da sociedade baseada na teoria positivista e darwinista social; a existência de uma sociedade hierárquica que atinge o negro, mas em especial, a mulher negra e a hierarquização dos valores que tendem a tratar a cultura negra e indígena como folclore; uma cultura em que domina a história europeia, mas pouco conhece dos povos pré-colombianos e africanos; a política como instrumento de manutenção do negro como trabalhador não qualificado; e a consequente marginalização do negro no que concerne ao trabalho, acesso à terra, sistema carcerário, prostituição, dentro desse processo de preterimento.

Gonzalez dialoga, assim, com as principais demandas do movimento negro contemporâneo, emergido no final dos anos 1970 no Brasil (PEREIRA, 2013). Nesse momento, o mito da democracia racial, assim como cientificamente disseminado na obra de Gilberto Freyre (1933), perdia sua força dentro do pensamento acadêmico brasileiro, em grande medida pelos esforços de Florestan Fernandes e sua obra "A integração do negro na sociedade de classes" (1965). Porém, o mito mantinha-se como fato entre as relações sociais brasileiras, permitindo a existência de um racismo dissimulado no qual todo indivíduo repudia sua manifestação e reconhece sua existência, nas palavras de Lilia Schwarcz "Todo brasileiro parece se sentir, portanto, como uma ilha de democracia racial, cercado de racistas por todos os lados" (1998, p. 180).

O mito da democracia racial e suas manifestações, com especial atenção para a educação eurocêntrica e a folclorização da cultura negra, serão, portanto, foco das

\footnotetext{
${ }^{4}$ Não serão transcritos na íntegra os diálogos presentes na Ata, o destaque será feito aos assuntos recorrentes e exigências postas como necessárias para a formulação da Constituição.
} 
discussões do movimento negro desse período, que, ao contrário dos organizados anteriormente, responsabilizava o Estado também como omisso e reprodutor do racismo institucional, e defendia ser responsabilidade do mesmo se posicionar contra essa estrutura (Garrido, 2017a).

É com base nessa perspectiva histórica que Lélia indica as motivações para o preterimento real e contemporâneo do negro, ou crioléu ${ }^{5}$ como ela gostava de chamar, evidentemente para criar constrangimento e colocar a semântica em favor de seu argumento. Nessa direção, a militante usa, como recurso, considerações sobre o censo de 1980:

O censo de 1980 está aí demonstrando que na nossa sociedade a hierarquia permanece. No que diz respeito ao acesso aos melhores salários nas diferentes profissões, vamos encontrar a relação hierárquica ao acesso aos melhores salários nas diferentes profissões, vamos encontrar a relação hierárquica e no primeiro plano está o homem branco, abaixo a mulher branca, em seguida o homem negro e, finalmente a mulher negra. É importante ressaltar que o racismo que existe na nossa sociedade tem que ser encarado olho no olho. Chega de ficarmos disfarçando que somos democratas raciais, que batemos no ombro do pretinho, mas não admitimos que case com nossas filhas, porque é demais! Chega desta postura paternalista que marca todas as relações da sociedade brasileira, as relações dos donos do poder com relação aos explorados, oprimidos e aos dominados; relações de compadrio, relações pessoais. (DIÁRIO DA ASSEMBLÉIA NACIONAL CONSTITUINTE - SUPLEMENTO AO N.62, 1987, p. 121)

No encerramento de sua palestra, Lélia deixou claro que o que estava em jogo era a concretização efetiva da isonomia social. Isonomia ali significava equidade, justiça, igualdade. Juridicamente, tratava-se de compreender que todos são iguais perante a lei, mas que situações desiguais devem ser compreendidas em suas especificidades, uma vez que não deve haver distinção de classe, grau ou poder econômico entre os homens e mulheres. Lélia recorre ao pedido de isonomia para a efetivação real de uma nação que considera a existência das desigualdades e se organiza pensando em superá-las.

\footnotetext{
${ }^{5}$ Como militante, Lélia Gonzalez passa a utilizar uma linguagem menos formal em textos e palestras; é uma opção, para a ativista, justificada por marcar a influência negra na cultura, em especial, na língua. $O$ uso de gírias e expressões cotidianas (a gente, cumé, pra, baratos, lance, transar) foram recursos utilizados na defesa dessa construção brasileira privilegiando aspectos negros, ao que chamava de "pretuguês" e, eram usados ora para se fazer entender para um público maior e menos elitizado, ora para utilizar da irreverência frente ao público academicista ou de jornalistas (RIOS; RATTS, 2010, p. 73-74).
} 
Em seguida, fez uso da palavra Helena Teodoro ${ }^{6}$ que diz concordar com o exposto por Lélia Gonzalez. Para Helena, as questões centrais para o debate em pauta eram: as diferentes formas de violência, em especial a violência simbólica no Brasil, que se constituía em um apartheid na prática, mesmo que não instituído; o alijamento da população negra do poder político; a necessidade do negro em se impor pelo brilhantismo para ter reconhecido seu mérito, uma vez que a sociedade e suas instituições tendem a encaixá-lo como categoria inferior; a dificuldade existente no país em lidar com as diferenças, via de regra discriminadas; a necessidade de conhecermos mais as lutas dos negros e suas culturas do passado e do presente, no Brasil e no continente africano; a necessidade de romper com a ideia de Brasil europeizado, pois a própria constituição natural fez criar aqui uma cultura tipicamente nova, sendo que esta estaria muito mais próxima da africana do que da portuguesa; a escola como espaço de “desbrasilização”, até mesmo na linguagem ensinada, que não promove a comunicação com quem não domina a forma culta e questiona, nesse momento, se os índices altíssimos de reprovação nas séries iniciais não seriam reflexo desse fenômeno; a Constituição como espaço de reversão para o alijamento dos setores pobres da população; e a necessária inserção da história do negro no Brasil e na África nos currículos. A conclusão do discurso de Teodoro reafirma a tônica de toda a sua fala: a necessidade de valorizar uma cultura brasileira altamente influenciada pelo continente africano e a promoção do negro à condição de cidadão.

Um ponto importante do discurso de Helena Teodoro estava no tocante da dificuldade de fazer com que os demais presentes e não negros entendessem o que sofre o negro:

Acho difícil para os companheiros desta Comissão, para as Excelências desta Comissão entenderem objetivamente a problemática do negro, mas acredito que possamos fazer um esforço para entender. Porque, na realidade, é muito importante ver o outro como outro, como ele é, mas no Brasil o outro sempre foi colocado no espelho a nossa semelhança. $O$ que significa o outro? O outro não existe, o Brasil tem tido toda uma tradição de homogeneizar, de fazer com que escamoteiem as diferenças,

\footnotetext{
${ }^{6}$ Ainda que o sujeito central do artigo seja Lélia Gonzalez, é importante compreender os debates que emergiram na reunião e com os quais ela dialogou; desta forma, o tópico explora também a argumentação da militante Helena Teodoro, que naquela data palestrou após Gonzalez.
} 
mas não há violências [sic] maior que não querer ver as diferenças. Quando temos uma Subcomissão do Negro, quando falamos na necessidade de estabelecer alianças, só se faz aliança quando há necessidade realmente de se trabalhar com as diferenças. (DIÁRIO DA ASSEMBLÉIA NACIONAL CONSTITUINTE - SUPLEMENTO AO N.62, 1987, p. 123)

A dificuldade de empatia entre ocupantes de cargos eletivos e a compreensão dos problemas enfrentados pela população negra brasileira, demonstram a dificuldade de fazer crer na legitimidade das demandas discutidas na Subcomissão no que tange à questão negra por parte dos políticos não próximos às militâncias.

O Presidente da Subcomissão, então, abre para perguntas, primeiramente dos representantes da sociedade civil presentes e, posteriormente, para os parlamentares. De acordo com o Ivo Lech, a ordem ficaria assim estabelecida para permitir aos que nunca possuíram direito à fala que se manifestassem sobre o assunto do qual teriam maior propriedade.

A primeira civil a fazer uso da palavra foi Maria das Graças dos Santos, representando o Movimento Negro Unificado. Ela discursou sobre a necessidade de romper com o mito da democracia racial, pois, na existência dele, as exigências de reparação são sempre desqualificadas pelo argumento de não existir distinção racial no país. Maria dos Santos questiona como seria possível realizar tal mudança. Na prática, a militante corrobora com o discurso de sua entidade, cuja bandeira, desde 1978, foi a de colocar em xeque o mito da democracia racial para que, então, se pudesse pensar em políticas afirmativas.

Lélia Gonzalez responde à colega de militância e reitera haver a necessidade de modificar dois veículos de informação para que o mito seja questionado: a televisão, que insiste em ocultar a presença negra ou tratar seus personagens de forma folclorizada ou sexualizada; e a escola, que necessita incorporar a história da África e dos afro-brasileiros, criando, então, a possibilidade da população conhecer de fato sua história.

O "Programa de Ação do MNU”, aprovado no IX Congresso Nacional, em Belo Horizonte, ocorrido entre os dias 13 e 15 de abril de 1990, ratificou a visão que a entidade possuía sobre o papel desempenhado pelos meios de comunicação: 
A classe dominante do país, exerce um controle quase absoluto sobre os meios de comunicação, pois, é através deles, que ela manipula as informações, forma opinião pública, estabelece costumes, cria modelos, reafirma e sustenta valores. Independente da nossa vontade, penetra nos lares levando sua própria visão política, social, econômica, cultural. Os Meios de Comunicação como a televisão, o rádio, os jornais, as revistas e os livros (de ficção e didáticos) desenvolvem a tarefa de legitimar, de tornar "natural e aceitável" a VIOLÊNCIA RACIAL CONTRA O NEGRO. (Texto mimeografado, disponibilizado por Milton Barbosa, 1990)

Ao estudar as telenovelas brasileiras, Joel Zito Araújo (2000) reitera a presença reduzida de papéis e o caráter, quase sempre, subalterno destinado às atrizes e aos atores negros. Para o pesquisador, a televisão brasileira reproduz um modelo euroamericano, sendo as telenovelas um exemplo desse fenômeno, esse ainda mais complexo dado o fato de ter se tornado um dos principais produtos culturais de exportação do Brasil.

Outra perspectiva que corrobora com a necessidade de reversão dos "papéis" destinados aos negros na mídia diz respeito ao ínfimo número de atrizes e atores negros que alcançaram status de personalidades no veículo televisivo e cinematográfico. A militante e jornalista Sandra Almada (1995) apresenta entrevistas de quatro atrizes brasileiras que, por serem negras, narram sua experiência aliada às questões raciais. Chica Xavier, Lea Garcia, Ruth de Souza e Zezé Motta não constituem narrativas homogêneas, nem poderiam. Porém, em comum, afirmam o número limitado de papéis oferecidos aos negros; o reforço de estereótipos; a pouca profundida dos personagens, que aparecem, em geral, sem história pessoal, como meros coadjuvantes; e o silenciamento da fala, inclusive no enquadramento da câmera.

Das quatro artistas protagonistas do livro Damas Negras, Léa Garcia e Zezé Motta afirmam ter envolvimento com o movimento negro. Léa Garcia foi integrante do IPCN (ALMADA, 1995, p. 99) e Zezé Motta aponta ter sido uma das fundadoras do MNU do Rio de Janeiro (ALMADA, 1995, p. 220). Ambas também destacam a importância que Lélia Gonzalez teve na construção do conhecimento crítico delas sobre a questão da raça. Cabe ainda apontar que Léa Garcia foi esposa de Abdias do Nascimento, e que Ruth de 
Souza teve um relacionamento com Abdias e foi integrante do TEN, embora afirme não ter participado das discussões políticas do grupo, apenas das artísticas.

Retornando à reunião da Subcomissão e para a resposta efetivada por Lélia Gonzalez sobre mídia, escola e mito da democracia racial:

[...] a televisão forma muito mais do que a escola. Mas, dentro da escola, nós temos que lutar, e já foi colocada, que é uma das nossas grandes reivindicações, lançada, inclusive, pelo $\mathrm{MNU}$, nesses anos todos de luta, a instauração da história da África, num currículo em todos os níveis e graus do ensino público e gratuito no Brasil, não é verdade? [...] porque um povo que desconhece a sua própria história, a sua própria formação, é incapaz de construir o futuro para si mesmo. (Lélia Gonzalez, DIÁRIO DA ASSEMBLÉIA NACIONAL CONSTITUINTE - SUPLEMENTO AO N. 62, 1987, p. 126)

A introdução da História da África e do afro-brasileiro é reivindicação unânime entre as entidades negras emergidas na década de 1970. Para elas, o pertencimento positivo é algo construído historicamente, tendo o conteúdo escolar papel decisivo nesse processo, como indica a citação de Regina Paim Pinto:

a educação está calcada nos valores do colonizador. A língua, os heróis, a história e, mesmo a religião que Ihes ensinam [aos alunos negros], não têm nada a ver com seu universo [...] a conseqüência mais grave desse processo de inculcação de novos valores [...] é a introjeção da sua inferioridade, da sua imagem negativa [...] (PINTO, 1987, p. 28)

Retornando à análise da Ata, o limite que as leis podem exercer no cotidiano também foi alvo de questionamento por parte de Murilo Ferreira (Fundação AfroBrasileira do Recife), ao que atentamente, Helena Teodoro ratificou afirmando:

Não se mudam os hábitos de um povo só pela Constituição. Por isso essa dimensão de luta nossa, por isso que nós temos que lutar por uma mudança de educação na escola, uma mudança na família, na comunidade, porque ninguém vai deixar de ser racista por causa de uma lei que diz que ele vai ser preso se ele for racista [...] Entra-se num ônibus; a polícia vai checar quem está no ônibus e só pede carteira para quem é negro. Onde é que está isso? Então, para a gente mudar isso tem que ser todo um processo de consciência do próprio povo e toda uma revisão de cada um de nós como agente da história [...] (Helena Teodoro, DIÁRIO DA ASSEMBLÉIA NACIONAL CONSTITUINTE, SUPLEMENTO AO N.62, 1987, p. 127) 
Portanto, a atuação da legislação não invalida ou torna desnecessárias novas formas de relações cotidianas, mas, ao mesmo tempo, as leis podem e devem direcionar a construção de novas formas de apreensão da cultura e de identificação do negro, auxiliando na transformação cotidiana. Conhecer os direitos, inclusive, seria salutar e necessário:

No Brasil, ninguém sabe dos seus direitos; é preciso trabalhar encima dos nossos direitos e apontando isso legalmente, na Constituição. É preciso estar com a Constituição na ponta da língua e a todo momento a ela reportar-se, como sendo um documento realmente que represente nossa realidade, os nossos anseios, a nossa vontade. (Helena Teodoro, DIÁRIO DA ASSEMBLÉIA NACIONAL CONSTITUINTE - SUPLEMENTO AO N. 62, 1987, p. 128)

Na mesma linha de raciocínio, Lídia Melo, representante do Centro de Estudos Afro-Brasileiros, se auto identifica aos demais como professora e insiste na necessidade de discutir a educação, em especial, os livros didáticos. O período, anos 1980, foi muito fecundo nas críticas aos materiais pedagógicos dentro da produção historiográfica, principalmente, no que se referia aos conteúdos dos livros didáticos e à debilidade do material. Igualmente, os livros didáticos estiveram sob a mira das demandas negras. Utilizados no Brasil como principal ferramenta de ensino7, eram (e são) constantemente apontados como objetos de discussão, seja pela ausência de conteúdos sobre história africana e afro-brasileira seja pela construção das narrativas eurocêntricas.

Assim, nos anos 1980, Joel Rufino - expoente por sua atuação de ativista, intelectual e que esteve presente na $10^{\text {a }}$ reunião da subcomissão - alertava que "os manuais didáticos são de fato entidades nefastas. Entidades nefastas que refletem, é evidente, uma percepção que a sociedade brasileira faz de si, uma concepção irreal, mas que sustenta o ser brasileiro, o fato de alguém se considerar brasileiro" (SANTOS, 1987, p. 99) e defendia que o melhor seria não utilizá-los. ${ }^{8}$

\footnotetext{
7 Fenômeno ampliado após a criação e ampliação do Programa Nacional do Livro Didático (1985) que, progressivamente, transformou o Brasil em maior comprador do gênero no mundo (GARRIDO, 2017b).

${ }^{8}$ Desde 2003, quando a atuação militante conquista a introdução da História da África e da cultura afrobrasileira no ensino, por força da Lei 10.639, os livros didáticos são mais uma vez reivindicados enquanto políticas públicas - que geram lucros exorbitantes às editoras - e que, portanto, devem ser revertidos em instrumentos de conscientização e conhecimento sobre conteúdos não consagrados, caso da África e dos afro-brasileiros (GARRIDO, 2017b).
} 
A relação mais direta entre demandas e possibilidade de inserção delas no texto da Constituição é alvo do questionamento de Mauro Paré, representante na ocasião, da Fundação Sangô. Ele diz a Gonzalez e Teodoro que

há algumas propostas, algumas sugestões que entendessem oportunas de ser incluídas nessa nova Carta Magna, de tal maneira que permita avançar em termos de direito. (Mauro Paré, DIÁRIO DA ASSEMBLÉIA NACIONAL CONSTITUINTE - SUPLEMENTO AO N. 62, 1987, p. 128)

A resposta da palestrante Helena Teodoro é específica na necessidade de focar na educação e cultura, inclusive:

1\% do Orçamento da União deveria ser para a cultura, e que, inclusive, não se colocasse como obrigatoriedade para exercício da profissão no Brasil o nível superior. Isso acaba com os artistas negros, praticamente, que não têm oportunidade de ir à escola. (DIÁRIO DA ASSEMBLÉIA NACIONAL CONSTITUINTE - SUPLEMENTO AO N. 62, 1987, p. 128)

Lélia, por sua vez, afirma que as sugestões não se focam exclusivamente em uma ou outra subcomissão e que Benedita da Silva teria em mãos um documento formulado pelo MNU sobre exigências a serem incluídas na Carta Magna. Infelizmente, não tive acesso ao documento mencionado, mas a construção das narrativas demonstra que as exigências e sugestões dos militantes giram em torno de eixos temáticos, como: educação; cultura; violência policial.

Antes de se encerrarem as questões e sugestões vindas das militâncias, entre os civis convidados, surgiu uma pequena situação de conflito. Januário Garcia questionou a pouca presença dos deputados nas discussões ali tratadas: segundo ele, dos 19 ligados à Subcomissão, apenas cinco ou seis estariam presentes, diminuindo, assim, a atenção dada às discussões desenroladas. Essa não seria a única vez que a ausência de constituintes e a impossibilidade de falar para todos os constituintes, independente da comissão que compunham, foi mencionada na Ata, inclusive por deputados, caso de Nelson Seixas (DIÁRIO DA ASSEMBLÉIA NACIONAL CONSTITUINTE - SUPLEMENTO AO N. 62, 1987, p. 132).

Sobre tal situação, o presidente deputado Ivo Lech se desculpou, mas argumentou se tratar do intenso trabalho que a Constituinte apresentava, sendo a ausência fruto da atenção dos deputados a uma série de outras exigências e, de forma alguma, havia falta 
de preocupação com o que ali estava em pauta. É válido mencionar que as primeiras reuniões da Subcomissão não ocorreram por falta de quorum, refletindo o desinteresse da Assembleia Nacional Constituinte e da mídia nos trabalhos efetuados na Subcomissão em questão (RODRIGUES, 2005, p. 51).

A insatisfação, com ares de queixa, de Januário Garcia - militante vinculado ao IPCN - foi seguida pela fala um tanto quanto polêmica do relator da Subcomissão. Afirmando-se surpreso com as exposições realizadas até o momento, Alceni Guerra dizia não observar o racismo como descrito pelos militantes. Prova disso seria o contato com uma empregada que prestou serviços em sua casa, quando criança; amigos que até mesmo se casaram com negras; a boa relação que manteve em sua vida profissional com pessoas negras, fossem elas subordinados dele ou seus chefes, embora não mencione quantos chefes negros de fato teve. Visivelmente o que era discutido ali não era apreendido como passível de atenção na elaboração da constituição como indica trecho que selecionei:

Então, me parece que o aspecto dramático de segregação colocado aqui, talvez seja um aspecto geracional, de geração, ou um aspecto circunstancial, local, geográfico. De qualquer maneira, como Constituinte, como Relator, nós somos obrigados a abrir o coração e fazer com que essas palavras nos toquem. [...] E não estaria disposto a propiciar, a colaborar para que a nossa Constituição tivesse qualquer artigo que propiciasse o favorecimento a qualquer segmento racial. Nem ao negro, nem ao branco, nem ao amarelo, nem ao índio. Eu acho que a igualdade perante a lei é de absoluta justiça. Liberdade com igualdade.. [...] A situação do negro no Brasil não é um problema de Constituição, é um problema de educação. (Alceni Guerra, DIÁRIO DA ASSEMBLÉIA NACIONAL CONSTITUINTE - SUPLEMENTO AO N. 62, 1987, p. 129. Grifos meus)

A resposta a tal assertiva veio de Lélia Gonzalez, famosa por argumentar de forma vigorosa em seus debates, o que, inclusive, Ihe rendeu o apelido que parecia gostar de ostentar, "negrinha atrevida". O primeiro contra-argumento vem da experiência de vida; Lélia menciona seu primeiro casamento e como a família branca daquele homem acreditava ser impossível aceitar que se tratava de uma união legítima, destinando a ela as alcunhas de "negra suja" e "prostituta". Segundo ela, era essencial desmistificar que somente a educação dará conta de resolver as desigualdades e experiências racistas que 
sofrem os negros brasileiros, reafirmando ser essencial sim a presença da Constituição como defensora de uma conduta que entenda as diferenças e legisle pensando nelas:

Gostaria de chamar a atenção para um aspecto fundamental aqui, e que é uma proposta essencial nesse, de movimento negro: dizer que a questão do negro no Brasil não é uma questão de Constituição, mas de educação e que depois a cultura vem - é desconhecer o que é cultura, em primeiro lugar; em segundo lugar, é ter uma visão muito atrasada, muito de senso comum a respeito do que seja a cultura. [...] até o presente momento, somos iguais perante a lei, mas quem somos nós? Somos as grandes populações dos presídios, da prostituição, da marginalização no mercado de trabalho. Nós queremos, sim, que a Constituição crie mecanismos que propiciem um efetivo "começar" em condições de igualdade da comunidade negra neste País. [...] Nós queremos, efetivamente, que a lei crie estímulos fiscais para que a sociedade civil e o Estado tomem medidas concretas de significação compensatória, a fim de implementar aos brasileiros de ascendência africana o direito à isonomia nos setores de trabalho, remuneração, educação, justiça, moradia, saúde, e vai por aí afora. Gente, nós não somos iguais perante essa lei, absolutamente, tanto que o sacrifício que fizemos para chegar aqui, nós que somos a maioria da população brasileira, por que não está cheio de negros aqui? (Lélia Gonzalez, DIÁRIO DA ASSEMBLÉIA NACIONAL CONSTITUINTE SUPLEMENTO AO N.62, 1987, p.129)

O momento parece delicado e o relator faz novamente uso da palavra; diz que cumpriu sua missão: a de provocador, a fim de esquentar o debate. Se agora estava convencido da legitimidade legal das propostas dos militantes e estudiosos, é pouco provável, mas ao menos externou a mentalidade da maior parte da população brasileira e, provavelmente, dos constituintes eleitos incumbidos de discutir e aprovar um texto constitucional.

O deputado José Carlos Sabóia faz uso da palavra em seguida e intermedia a discussão acalorada. Afirma compreender as colocações do colega Alceni Guerra, pois as multiplicidades das relações no Brasil devem ser levadas em consideração. Contudo, em seguida, afirma concordar com as expositoras, mencionando um apreço especial às palavras de Florestan Fernandes, também deputado constituinte, mas não participante daquela subcomissão. O deputado finaliza afirmando que se nem mesmo o movimento negro foi capaz de criar um movimento de massa, como fariam os constituintes para provar a legitimidade da defesa das demandas negras? 
Não me vem à cabeça a possibilidade, ainda, de nós transformarmos as reivindicações negras dos movimentos negros do Brasil, do direito à cidadania no Brasil, que o negro não tem realmente, como é que nós podemos dar esse salto para a luta política de massa. [...] A minha preocupação é um pouco mais urgente: é a de que como nós vamos sensibilizar, como nós vamos mexer na consciência branca dos Srs. Constituintes nem sempre brancos? (José Carlos Sabóia, DIÁRIO DA ASSEMBLÉIA NACIONAL CONSTITUINTE - SUPLEMENTO AO N. 62, 1987, p. 132)

As militâncias negras, antes mesmo de iniciados os trabalhos da Constituinte, receavam que a compreensão de deputados e senadores (em sua maioria homens brancos com alto poder aquisitivo) fosse limitada das necessidades da população negra, prova disso foi a intensa tentativa de lograr êxito nas eleições para o processo, em grande parte frustradas (RIOS, 2014, p.157). Já nos trabalhos dos constituintes eleitos, os indícios da fragilidade da sensibilização aparecem de forma evidente nos diálogos travados entre os militantes e os ocupantes de cargos eletivos ali presentes, inclusive partindo a dúvida de um dos ocupantes de cargo eletivo como mostra a citação. Mas não se trata de uma unanimidade. O constituinte Hélio Costa, por exemplo, informa que iria apresentar à comissão uma proposta de criação de um sistema de cotas, baseada na experiência dos Estados Unidos. Outro exemplo de que havia perspectivas positivas é a fala de Carlos Alberto Caó que, na época, fazia parte da Comissão Ciência e Tecnologia:

eu e o meu companheiro Olívio Dutra queremos informar à Mesa desta Subcomissão e às demais pessoas aqui presentes, que vamos tomar a iniciativa de propor que, entre as audiências públicas que ainda serão feitas pela nossa Subcomissão se realize uma especificamente para discutir o problema do negro correlacionado com Ciência e Tecnologia e especificamente relacionado com o problema de comunicação. De nossa parte seria um esforço individual nosso. Como nós temos como Relator da Comissão de Direitos e Garantias Individuais o Constituinte Lysãneas Maciel, que pertence aos quadros do PDT, tenho plena certeza e convicção de que não contaremos com a menor resistência deste Constituinte, para que as instituições representativas do movimento negro possam ali também discutir e colocar a sua posição. (Carlos Alberto Caó, DIÁRIO DA ASSEMBLÉIA NACIONAL CONSTITUINTE SUPLEMENTO AO N. 62, 1987, p. 133)

O deputado eleito pelo PDT (Rio de Janeiro) reafirma a posição do Partido Democrático Trabalhista com relação às questões étnico-raciais brasileiras. Vale indicar 
que o bom relacionamento de Leonel Brizola, idealizador do partido, com Abdias do Nascimento originou um compromisso do PDT com as causas negras desde sua formação. Ademais, o próprio deputado Carlos Alberto Caó foi um dos defensores dos direitos dessa parcela da sociedade sendo sua atuação no plenário da Constituinte fundamental para a criminalização do racismo (RODRIGUES, 2005, p. 56).

De qualquer modo, é interessante observar como as exigências dos militantes negros, que em suma se constituíam no acesso à cidadania, ao direito de isonomia e a medidas compensatórias, esteve sempre dependente da sensibilização daqueles que tinham o poder de legislar.

O poder de sensibilização e de provocação esteve sempre presente nas argumentações de Lélia Gonzalez. Se os trabalhos da tarde, por exemplo, iniciam-se num "bate papo" entre os gaúchos constituintes, Ivo Lech e Ruy Nedel, sobre as dificuldades enfrentadas pelos imigrantes alemães e os negros do sul (escravizados no período, mas não mencionado pelos deputados), e as afinidades surgidas desse contexto entre esses dois grupos, Lélia Gonzalez intervém, realiza enfático discurso sobre a construção do país pelas mãos negras, e finaliza: "Só um detalhezinho: há uma diferença entre ser imigrante e ser escravo" (Lélia Gonzalez, DIÁRIO DA ASSEMBLÉIA NACIONAL CONSTITUINTE SUPLEMENTO AO N. 62, 1987, p. 138).

Mas a ironia não fica por conta apenas de Lélia Gonzalez. Quando aberta a leitura das sugestões das militâncias e constituintes mais familiarizados com o preterimento do segmento negro da sociedade, Benedita tenta instigar discussões e recebe a seguinte resposta de Alceni Guerra:

A dificuldade de polemizar, como quer a Constituinte Benedita, tem algumas razões bastante claras de ser. A primeira é que ninguém está disposto a enfrentar esta metralhadora giratória que é Lélia Gonzalez. Eu tive a oportunidade de manhã e confesso que não me sai bem [...] e depois, permita-me o elogio, eu até não entendo como é que num tempo tão curto a proposta - quero começar a acreditar agora que não foi de hoje e manhã para cá - tenha vindo tão clara, tão concisa e perfeita e acho que sobre as coisas perfeitas temos uma certa dificuldade de debater. (DIÁRIO DA ASSEMBLÉIA NACIONAL CONSTITUINTE SUPLEMENTO AO N. 62, 1987, p. 139. Grifos meus) 
No geral, a palavra de ordem na $7^{\text {a }}$ Reunião da Subcomissão era cidadania, negada historicamente aos negros no Brasil. Igualmente, os debates indicavam a necessária criação de uma legislação que manifestasse que todos são portadores de direitos, mas que desiguais não podem ser tratados como iguais, pois isso não configuraria a famigerada isonomia, recorrentemente mencionada por militantes e constituintes em suas falas.

Dentro dessas questões gerais, apontou-se a necessidade de uma estrutura escolar (livros, práticas didáticas, mentalidade) que estimulasse o conhecimento de uma História não estereotipada; a criação de mecanismos de resgate da cultura contra a folclorização da mesma; a necessidade de disponibilizar vagas no mercado de trabalho e nas escolas de excelência; tornar o racismo crime e não contravenção, como era previsto pela Lei Afonso Arinos; tornar os meios de comunicação instrumentos educativos e não mais reprodutores de estereótipos; a necessária reforma agrária, em especial, atenção aos remanescentes de quilombos; o reconhecimento de uma sociedade plural.

\section{Considerações Finais}

Findado o processo de discussão e aprovação da Constituição de 1988, os militantes da causa negra tinham o que comemorar. O racismo, pela primeira vez no país, tornava-se crime (Art. $5^{\circ}$ inciso XLII); as terras quilombolas e as manifestações culturais afro-brasileiras foram determinadas como legítimas e necessárias de proteção (Art. 215); e a educação passava a considerar contribuições de diferentes culturas e etnias na formação do país (art. 242, §1 $1^{\circ}$ ).

Segundo Lucas Brandão (2011, p. 124), 42\% do texto constitucional foi decidido nas Comissões Temáticas; 26\% na Comissão de Sistematização; e 32\% no plenário, o que revela a importância da organização e participação da sociedade civil nas discussões do texto constitucional. Porém, como visto na discussão travada em 19 de maio de 1987, na Subcomissão que analiso, grande parte das propostas ali colocadas ficaram de fora da redação final da Carta Magna. Ainda assim, devemos considerar que a credibilidade erigida pela trajetória e arguição de militantes, cujo texto focou no exemplo de Lélia 
Gonzalez, foram colocadas em uso político na Assembleia Constituinte, e garantiram ganhos significativos, dentre eles, visibilidade às demandas do movimento negro.

O artigo contribui também para observar como as atribuições do Estado têm sido ressignificadas e, conjuntamente, imputam novos contornos à história política:

\begin{abstract}
À medida que os poderes públicos eram levados a legislar, regulamentar, subvencionar, controlar a produção, a construção de moradias, a assistência social, a saúde pública, a difusão da cultura, esses setores passaram, uns após os outros, para os domínios da história política. [...] A prova disso [que o político se refere a verdadeira realidade] está na atração cada vez maior que a política e as relações com o poder exercem sobre agrupamentos cuja finalidade primeira não era, contudo, política: associações de todos os tipos, organizações socioprofissionais, sindicatos e igrejas, que não podem ignorar a política. (RÉMOND, 2003, p. 24)
\end{abstract}

Momentos de reflexão, como a comemoração dos 30 anos da Constituição, devem ser aproveitados para a realização de balanços dos ganhos legislativos e, sobretudo, devem auxiliar a compreensão da multiplicidade de sujeitos históricos, de suas ações, estratégias e conquistas.

\title{
Referências
}

ALBERTI, Verena; PEREIRA, Amilcar Araújo. Histórias do movimento negro no Brasil: depoimentos ao CPDOC. Rio de Janeiro: Pallas; CPDOC-FGV, 2007.

ALMADA, Sandra. Damas negras: sucesso, lutas, discriminação. Chica Xavier, Léa Garcia, Ruth de Souza, Zezé Motta. Rio de Janeiro: MAUAD, 1995

ARAÚJO, Joel Zito. A negação do Brasil: o negro na telenovela brasileira. São Paulo: Ed Senac, 2000.

BAIRROS, Luiza. Lembrando Lélia Gonzalez. In: WERNECK, Jurema; MENDONÇA, Maisa; WHITE, Evelyn (Orgs.). O livro da saúde das mulheres negras: nossos passos vêm de longe. Rio de Janeiro: Pallas; Criola; Global Exchange, 2006, p. 42-61. 
BARRETO, Raquel de Andrade. Aquela “negrinha” atrevida: Lélia Gonzalez e o movimento negro brasileiro. In: FERREIRA, Jorge; REIS, Daniel Aarão. (Orgs.) Revolução e democracia (1964...). Rio de Janeiro: Civilização Brasileira, 2007.

\section{BARRETO, Raquel de Andrade. Enegrecendo o feminismo ou feminizando a raça:} narrativas de libertação em Angela Davis e Lélia Gonzáles. 2005. Dissertação (Mestrado em História Social da Cultura). - Centro de Ciências Sociais, Pontifícia Universidade Católica do Rio de Janeiro, Rio de Janeiro, 2005.

BASÍLIO, Luciana Regina. Desigualdade racial e políticas de inclusão (1988-2002): uma perspectiva política acerca da condição do negro. 2004. Dissertação (Mestrado em Ciências Sociais) - Ciências Sociais, Universidade Estadual de Londrina, 2004.

\section{BRANDÃO, Lucas Coelho. Os movimentos sociais e a Assembleia Nacional Constituinte} de 1987-1988: entre a política institucional e a participação popular. 2011. Dissertação (Mestrado em Sociologia) - Universidade de São Paulo, 2011.

CARDOSO, Cláudia Pons. Amefricanizando o feminismo: o pensamento de Lélia Gonzalez. Revista Estudos Feministas, Florianópolis, v. 22, n. 3, p.965-986, set. 2014.

DIÁRIO DA ASSEMBLÉIA NACIONAL CONSTITUINTE: Suplemento ao n.62. [7 $7^{\circ}$ Reunião da Subcomissão dos Negros, Populações Indígenas, Pessoas deficientes e Minorias] 20 de maio de 1987. Disponível em: < http://imagem.camara.gov.br/Imagem/d/pdf/ sup62anc2omai1987.pdf\#page=1201987> Acesso em: 19 de maio de 2015 .

FERNANDES, Florestan. A integração do negro na sociedade de classes: o legado da “raça branca". V. 1. São Paulo: Editora Dominus, 1965.

FREYRE, Gilberto. Casa-Grande \& Senzala. 20.ed. São Paulo: Círculo do Livro, 1980.

GARRIDO, Mírian C. M. Escravo, africano, negro e afrodescendente: a representação do negro no contexto pós-abolição e o mercado de materiais didáticos (1997-2012). São Paulo: Alameda, 2017b.

GARRIDO, Mírian C.M. Nas constituições dos discursos sobre afro-brasileiros: uma análise histórica da ação de militantes negros e dos documentos oficiais voltados à promoção do negro brasileiro (1978 a 2010). 2017. Tese (Doutorado em História) - Universidade Estadual Paulista “Julio de Mesquita Filho”, Assis, $2017 a$.

GONZALÉZ, Lélia; HASENBALG, Carlos. Lugar de negro. Rio de Janeiro: Marco Zero, 1982.

PEREIRA, Amilcar Araújo. O mundo negro: relações raciais e a constituição do movimento negro contemporâneo no Brasil. Rio de Janeiro: Pallas, Faperj, 2013. 
PINTO, Regina Pahim. A Educação do negro: uma revisão da bibliografia. Cadernos de Pesquisa Carlos Chagas, São Paulo. n. 62, ago. 1987, p.28.

PROGRAMA DE AÇÃO DO MNU. Aprovado no IX Congresso Nacional em Belo Horizonte. 13 a 15 de abril de 1990. Documento disponibilizado pelo militante e fundador do MNU Milton Barbosa (06/11/2014).

RATTS, Alex; RIOS, Flavia. Lélia Gonzalez. São Paulo: Selo Negro, 2010.

RÉMOND, René. O retorno do político. In: CHAVEAU, Agnes; TÉTARD, Philippe. Questões para a história do presente. Bauru: EDUSC, 1999.

RÉMOND, René. Uma história presente. In: REMOND, René. (Org.) Por uma história política. 2.ed. Rio de Janeiro: Editora FGV, 2003.

RIOS, Flavia Mateus. Elite política negra no Brasil: relação entre movimento social, partidos políticos e Estado. 2014. Tese (Doutorado em Sociologia) - Universidade de São Paulo, 2014.

RODRIGUES, Tatiane Consentino. Movimento negro no cenário brasileiro: embates e contribuições à política educacional nas décadas de 1980-1990. 2005. Dissertação (Mestrado em Ciências Sociais) - São Carlos, UFSCar, 2005.

SANTOS, Joel Rufino dos. “Livro Didático: um mal necessário?” Cadernos de Pesquisa Carlos Chagas. São Paulo. n. 63, nov. 1987, p.99-100.

SANTOS, Joel Rufino dos. Livro didático: um mal necessário? Cadernos de Pesquisa Carlos Chagas. São Paulo. n. 63, p.99, nov., 1987,

SCHWARCZ, Lilia Moritz. Nem preto nem branco, muito pelo contrário: cor e raça na intimidade. In: NOVAIS, Fernando A.; SCHWARCZ, Lilia Moritz. (Orgs) História da vida privada no Brasil: contrastes da intimidade contemporânea. São Paulo: Companhia das Letras, 1998, p.180.

SILVA, Wilton Carlos Lima. Vivos, uni-vos!: os ecologistas e a Assembleia Nacional Constituinte (1986-1988). 1993. Dissertação (Mestrado em Sociologia) - Universidade Estadual de Campinas, 1993.

VIANA, Elizabeth do Espírito Santo. Relações raciais, gênero e movimentos sociais: o pensamento de Lélia Gonzalez (1970-1990). 2006. Dissertação (Mestrado em História Comparada) - Instituto de Filosofia e Ciências Sociais, Universidade Federal do Rio de Janeiro, Rio de Janeiro, 2006. 
XAVIER, Giovana. Brancos de almas negras?: beleza, racialização e cosmética na imprensa negra pós-emancipação (EUA, 1890-1930). 2012. Tese (Doutorado em História) Universidade Estadual de Campinas, 2012.

Recebido em 06/03/2018 Aprovado em 17/07/2018 